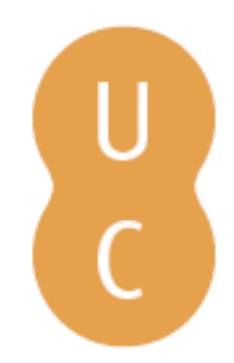

\title{
pommalina
}

\section{Uso da informação por empresários de microempresas alimentícias do estado de Minas Gerais - metódo de analise sense-making}

Autor(es): $\quad$ Araujo, Nelma Camêlo; Costa, Marilia Damiani

Publicado por: Imprensa da Universidade de Coimbra

URL

persistente: URI:http://hdl.handle.net/10316.2/31968

DOI: $\quad$ DOI:http://dx.doi.org/10.14195/978-989-26-0869-3_42

Accessed : $\quad$ 26-Apr-2023 11:16:57

A navegação consulta e descarregamento dos títulos inseridos nas Bibliotecas Digitais UC Digitalis, UC Pombalina e UC Impactum, pressupõem a aceitação plena e sem reservas dos Termos e Condições de Uso destas Bibliotecas Digitais, disponíveis em https://digitalis.uc.pt/pt-pt/termos.

Conforme exposto nos referidos Termos e Condições de Uso, o descarregamento de títulos de acesso restrito requer uma licença válida de autorização devendo o utilizador aceder ao(s) documento(s) a partir de um endereço de IP da instituição detentora da supramencionada licença.

Ao utilizador é apenas permitido o descarregamento para uso pessoal, pelo que o emprego do(s) título(s) descarregado(s) para outro fim, designadamente comercial, carece de autorização do respetivo autor ou editor da obra.

Na medida em que todas as obras da UC Digitalis se encontram protegidas pelo Código do Direito de Autor e Direitos Conexos e demais legislação aplicável, toda a cópia, parcial ou total, deste documento, nos casos em que é legalmente admitida, deverá conter ou fazer-se acompanhar por este aviso.

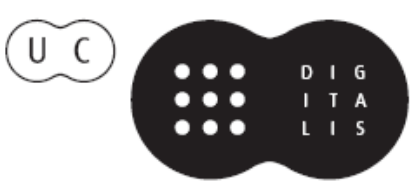


Maria Manuel Borges

Elias Sanz Casado

Coordenação

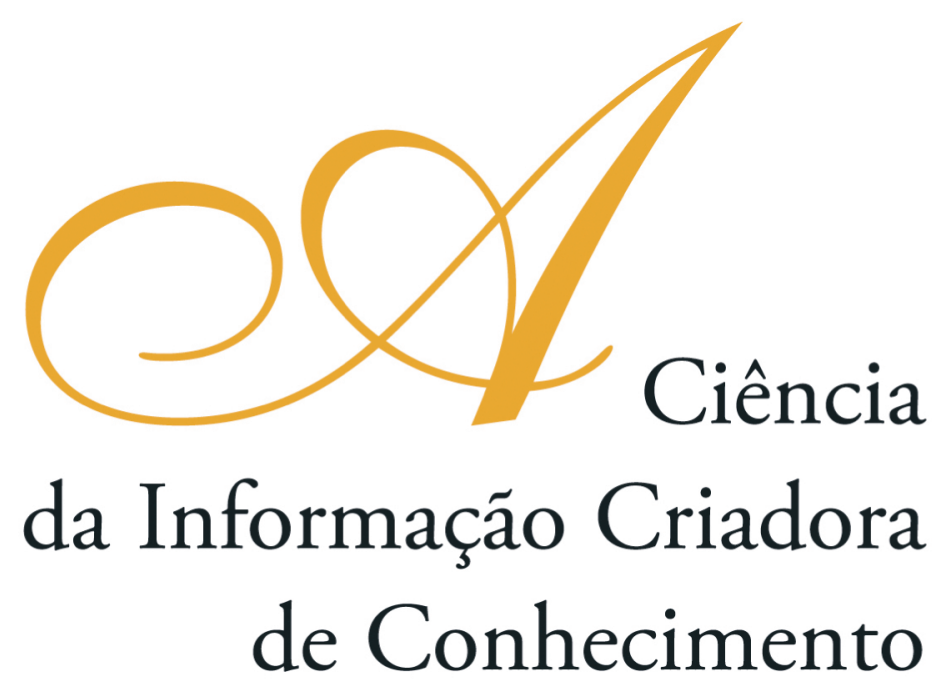

Vol. I I

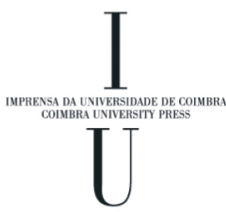

- COImbra 2009 


\title{
USO DA INFORMAÇÃo POR EMPRESÁRIOS DE MICROEMPRESAS ALIMENTÍCIAS DO Estado de Minas Gerais - metódo de analise sense-making
}

\author{
Nelma Camêlo Araujo \\ Universidade Estadual de Londrina (Brasil) \\ Marilia Damiani Costa \\ Universidade Federal de Santa Catarina (Brasil)
}

\section{Introdução}

Nas organizaçóes, informaçóes são geradas, organizadas e difundidas em todos os seus processos, mesmo quando não são sistematizadas. Para Rezende (2002) os conceitos estruturais das empresas estáo voltados para qualidade, produtividade e competitividade, e, a importância em "gerenciar de maneira inteligente as informaçóes obtidas e o conseqüente conhecimento gerado e incorporado pela empresa" partindo de seus processos, "passa a ser diferencial estratégico" na organização.

A informação no ambiente interno das microempresas é tratada e administrada de acordo com a necessidade imediata percebida pelo empresário, ou seja, não há um controle sobre a necessidade, organização e uso dessas informaçóes.

Nesse contexto, os Serviços de Informação Tecnológica, via de regra, passam a assumir características de Centros de Análise da Informação, tendo em vista que, para o efetivo atendimento às micro, pequenas e médias empresas, torna-se necessário adequar as informaçôes ao nível da assimilação desses usuários.

No Brasil a preocupação em subsidiar com informaçóes às micro, pequenas $\mathrm{e}$ médias empresas, contou com apoio do governo Federal ao longo das três últimas décadas (desde 1980). A partir de 1990, algumas instituiçóes de pesquisa e entidades ligadas à indústria começaram a ofertar serviços de informação tecnológica, dentre eles o Serviço de Resposta Técnica.

Dentre as instituiçôes de pesquisa no Brasil que atuam na oferta do serviço de resposta técnica, destaca-se a Fundação Centro Tecnológico de Minas Gerais - CETEC, pela Unidade de Atendimento em Informação e Tecnologia (UAITec), que atua desde 1972.

O Estado de Minas Gerais está entre os primeiros, no setor de laticínio no país. No período de 2000 a 2002, O Instituto de Desenvolvimento Industrial - INDI, de Minas Gerais, priorizou no Estado, projetos na área de alimentos, principalmente no setor de massas, panificaçáo, lacticínios e compotas. Acredita-se que tal fato seja impulsionador da demanda de perguntas de empresários de microempresas ao Serviço de Resposta Técnica do UAITec/CETEC, no período de 2001 a 2003. 


\section{Objetivos e metodologia}

O objetivo desta pesquisa foi "analisar o uso efetivo da informação obtida no Serviço de Resposta Técnica pelos empresários de microempresas alimentícias do Estado de Minas Gerais". Trata-se de um estudo de caso desenvolvido a partir da informação fornecida pelo Serviço de Resposta Técnica, da Unidade de Atendimento em Informação e Tecnologia (UAITec) da Fundação Centro Tecnológico de Minas Gerais (CETEC), em Belo Horizonte/MG.

A amostra da pesquisa foi do tipo intencional, composta por 16 empresários de microempresas do setor alimentício do Estado de Minas Gerais.

A pesquisa apresentada é exploratória, descritiva, de cunho qualitativo, fazendo-se uso do método sense-making de Dervin (1983) para coleta de dados e do modelo de uso da informação de Choo (2003) como parâmetro para estruturar a análise dos dados. Os dados coletados foram realizados por intermédio de entrevistas semi-estruturadas, do tipo micro-moment time line interview, em contato direto com o empresário em seu empreendimento, sendo 5 do interior de Minas Gerais, 7 da região metropolitana de Belo Horizonte e 4 da área central de Belo Horizonte.

\section{Resultados e conclusões}

Ao final da pesquisa, verificou-se que as necessidades de informação, que levaram ao uso efetivo da informação, estavam relacionadas à sua base de conhecimentos, registradas na matriz "base do conhecimento dos entrevistados". Tais necessidades estavam relacionadas às classes de uso: compreensão do problema, esclarecimentos e confirmativa.

A visão que o usuário/empresário tem do problema é, portanto, fundamental para entender como ele realiza a busca e influencia também no uso da informação que lhe é fornecida.

$\mathrm{Na}$ busca de informaçóes, os entrevistados recorreram principalmente às fontes informais, ou seja, acessaram diretamente pessoas que dispunham de conhecimentos relacionados às suas dúvidas ou necessidades. Estas pessoas foram preferencialmente outros empresários do ramo ou pessoas que atuam no setor de alguma forma, sendo também citados amigos e parentes e, por último, as instituiçóes como o SEBRAE e o Projeto Mãos de Minas.

Quanto aos empresários que não utilizaram a informação fornecida pelo Serviço de Resposta Técnica, foi constatado que eles pretendiam usá-la para aplicaçôes fora de suas competências empresariais, implicando no desenvolvimento de pesquisas em laboratórios ou em outros investimentos no empreendimento, não tendo condiçóes naquele momento de completar o ciclo informacional de uso efetivo da informação.

Concluiu-se que os Serviços de Informação, do tipo Resposta Técnica, que atendem às micros e pequenas empresas são fundamentais para apoiar a adequação dos produtos, dessas empresas, ao mercado nacional, principalmente na área de alimentos, pois atingem uma parcela significativa da sociedade. Portanto, a continuidade de pesquisas, com essa abordagem, na área de ciência da informação, poderá contribuir para o aprimoramento desses serviços. 


\section{Referências bibliográficas}

CHOO, Chun Wei. A organizaçáo do conhecimento. São Paulo: SENAC, 2003.

DERVIN, Brenda. An over view of sense-marking ressearch: concepts, methods and results to date. In: International Comunications Association Annual Meeting, 1983, Dalas. Disponível em: < http://www.eca. usp.br/eca/profSueli/sensemaking.Html > Acesso em: 12 maio 2004.

REZENDE, D.A . Tecnologia da Informaçáo integrada à inteligência empresarial: alinhamento estratégico e análise da prática nas organizaçôes. São Paulo: Atlas, 2002. 